\title{
End-of-life issues for a modern India - Lessons learnt in the West
}

\author{
Vinod K. Puri
}

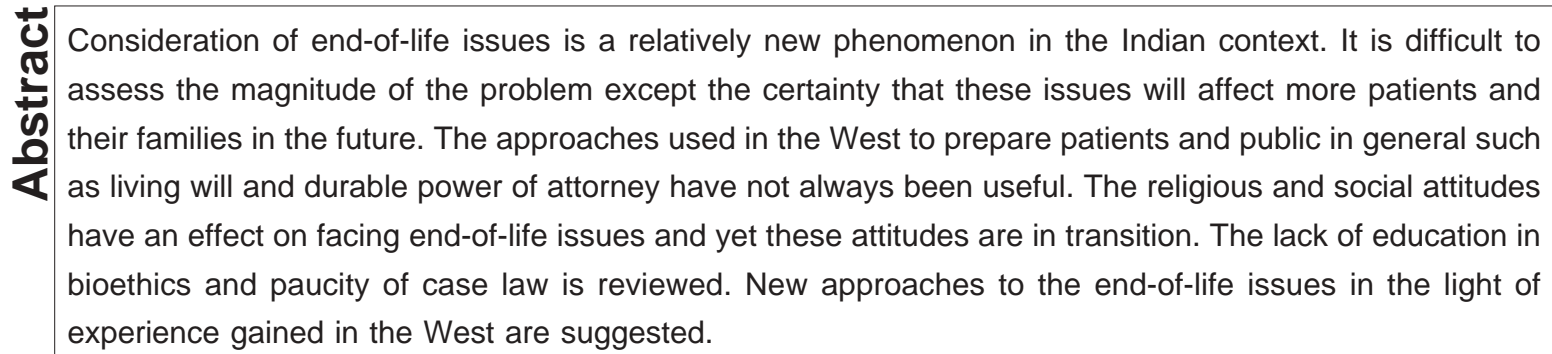

Key Words: CPR, DNR, DPA, Ethics, Living will

\section{Introduction}

Most commentators about healthcare especially expensive intensive care in India would justifiably worry more about its availability rather than too much care! Still we must recognize that transformation of the dying process is taking place in India at a pace much faster than imagined just a few years ago. Even if for most of the Indians, the Terri Schiavo case in the USA in early 2005 appeared to be foible of a rich nation, the issues may be closer to home. Mani and Kapadia refer to two cases. ${ }^{[1,2]}$ The supreme court of India seems to have issued contradictory judgments in the case of Gian Kaur vs State of Punjab State. ${ }^{[1]}$ The court stated that the right to live cannot be interpreted to include the right to die an unnatural death curtailing the natural life span. How did the court arrive at the conclusion that removal from life support in persistent vegetative state was cutting short 'a natural life span?' In an earlier opinion the justices acknowledged that '....a person cannot be forced to enjoy the right to life to his detriment, disadvantage or dis-

\footnotetext{
From:

St John Health System, Providence Hospital and Medical Centers, Southfield, MI, USA

Correspondence:

Vinod K Puri,

1450 Covington Rd, Bloomfield Hills, MI 48301, USA.
}

E-mail: amritsari@hotmail.com like.' The essence of developing census on bioethical issues is to reconcile differing points of view, debate the ethics and logic of legal opinions and to adopt pragmatic but principled solutions. It is obvious that the justices need to reconcile the views they have expressed about article 21 of the Indian constitution. The differences between withdrawal of life support as distinct from suicide or murder appear to escape the sensibilities of some jurors.

It is not surprising that most of the articles Mani cites are US references for legal opinions. His excellent review discusses the ethical principles such as autonomy, beneficence, and nonmalfeasance and double effect. Many of these concepts have evolved from the JudeoChristian ethos and from the work of European philosophers over many centuries. ${ }^{[3,4]}$ An equally vigorous effort to address bioethical issues raised by rapid advances in medicine has been joined by ethicists, physicians, and law people. ${ }^{[5-9]}$ The medical students receive education in ethics. The residents and practicing physicians continue to receive instruction during their training and years of practice.

The principles of informed consent and autonomy are

Free full text available from www.ijccm.org 
inter-related and are likely to be considered universal human values in the modern world. Therefore, the application of these ethical principles to Indian medical practices is inevitable in the future. And yet it is appropriate to enquire about the experience gained in the West.

The use of 'do not resuscitate' (DNR) orders by mid1970s, to avoid cardiopulmonary resuscitation (CPR) has followed universal adoption of CPR in the American hospitals in early 1960s. Thus in America, we have had over 30 years of experience in utilizing DNR orders. ${ }^{[10,11]} A$ great deal of published data to assess its impact in avoiding CPR in hospitalized patients exists. There certainly are some important lessons that have been learnt in dealing with the dying patients. It is worth considering whether we can apply some of these lessons to the Indian patients as critical care becomes more commonplace. Suggestions for new or modified hospital policies are provided in the light of the experience.

\section{DNR orders}

Kapadia et al. have recently indicated that withdrawal or withholding of intensive care in the terminally ill patients in India has not been studied. ${ }^{[2]}$ Indian data are sparse. Except for a single center study by Mani, little data exist. ${ }^{[1]}$ This author reported that $78 \%$ of the patients received full resuscitation. When we compare $11 \%$ of the elderly patients in the large SUPPORT study who received CPR or $3 \%$ in a more recent study, we realize practices in India are far behind those in the developed countries. ${ }^{[11-13]}$ DNR orders in Mani's study existed only for $1.6 \%$ of all ICU deaths with another $1.6 \%$ patients had orders to withhold life support. Kapadia et al. also point out the important differences between public and private hospitals. Majority of the patients dying in the hospital were transferred to the ICU before death in private hospitals compared with public or cancer hospitals. Terminal care was limited in $19 \%$ of the cases in the former and $40-50 \%$ of the private cases. On the other hand, Heyland and colleagues documented that $66 \%$ of the deaths in Canadian hospitals were preceded by gradual deterioration and $90 \%$ by withdrawal of some therapy. ${ }^{[11]}$ It is quite difficult to estimate the magnitude of the problem in India except to speculate that it is common.

\section{Brain-death law}

The brain-death laws passed in all 50 states of US have had a definite impact on the practice of medicine. It allowed physicians to establish two sets of criteria for diagnosis of death - the traditional cardio-respiratory criteria of cessation of circulation and breathing, and the brain-death criteria of cessation of cortical and brainstem activity. The equivalence of these criteria allows the removal of life-support systems. Historically, transplant professionals had a major role in convincing the legislature regarding need for passage of the state laws. However, clinical brain-death criteria are routinely used for diagnosis and management in the intensive care units irrespective of whether the patient is a potential organ donor. The Indian law restricting brain-death application to only potential organ donors is too limited in its scope and needs to be modified.

\section{CPR in all dying patients?}

To avoid some of the pitfalls detailed when universal CPR is practiced in the hospitalized patients, an explicit standard of care is suggested that all dying patients need not be subjected to CPR. On the other hand, justification for performance of CPR should be sought in all cases. This is one quality of care measure which is currently has not been implemented in the US.

Since implied consent in hospitalized patients is considered to be the reason for universal CPR, an innovative change in hospital policy is required. In that regard, a proposal is made that presumed consent for CPR should be limited to patients who are not likely to suffer a cardiopulmonary arrest in the hospital. In all seriously ill patients, physicians should be required to determine within $24 \mathrm{~h}$ of hospital admission, if the patient is likely to suffer a cardiopulmonary arrest and his/her chances of survival after a CPR. This information should be recorded and conveyed to the family members. Of course, this would trigger a dialogue regarding advisability of CPR in case of a cardiac arrest. This change in policy will restore therapeutic rationale to CPR. To protect against low frequency events, it will still cover patients with unexpected deterioration.

\section{Advanced directives}

As pointed out in the accompanying article, DNR orders are not the panacea for avoiding suffering at the end-of-life. ${ }^{[14]}$ DNR orders may be considered first and necessary step to convey patients' wishes to the medical personnel communication of patient's wishes to the 
physicians and nurses regarding CPR, mechanical ventilation, and artificial feedings are amongst the most important decisions. Advance directives such as durable power of attorney (DPA) for medical decisions are devices that have been extensively promoted in America. Advance directives, which designate a person to make decisions regarding end-of-life care are legal in all states. Living will which codifies patient's desires in simple but often vague language has a dismal record. ${ }^{[15]}$ Fagerlin and Schneider point out that only $18 \%$ of Americans have living wills. But more importantly, they have not proved results that recompense costs, and it should be rescinded. In the Indian context, it must be recognized that surrogate decision-makers such as family members and close advisers may carry more influence than is seen in the West. In general, actual practices regarding surrogate decision-making in India may be closer to reality in the American hospitals.

\section{Demands for marginally effective treatments}

It is now recognized that the demand for heroic treatments or marginally effective therapies outweighs the older concerns about continuation of unwanted treatments. ${ }^{[9]}$ Most of the time the demand is likely to come from the surrogates. But even if a patient makes patently irrational demands, medical personnel are under no obligations to carry them out. To deal with such demands, enlightened hospital policies should allow unilateral DNR decisions by the physicians. The patient or surrogates should be informed of these decisions, reasons documented and routinely reviewed by the ethics committees. In case of disagreement between the physician and surrogates, hospital policies should allow for transfer of care to another physician or institution. Ethics committees should be obligated for expeditious and timely review of cases and physicians mandated to cooperate for review of cases. In the Indian context, education in bioethical issues and establishment of institutional ethics committees will require a major effort. Major institutions in the metropolitan areas with full academic support should spearhead the voluntary effort.

As safeguards, all aspects of care in DNR patients should be routinely reviewed for indications, mortality, and morbidity. Examples of these include tracheostomy, feeding tubes, dialysis catheters, prolonged antibiotics usage, debridement of bedsores, and parenteral nutrition. DNR decisions whenever rescinded should be re- viewed for appropriateness. Peer review process should cover unnecessary CPRs and practices monitored. The purpose of these policies would be to scrutinize practices that result in excessive use of hospital resources and ordinarily will remain un-examined if patients just before death are designated DNR.

It is stipulated that patients in persistent vegetative state should automatically be presumed to have DNR designation and excluded from intensive care. The rationale for this important policy is detailed in the accompanying article. ${ }^{[12]}$

\section{Law and end-of-life decisions}

Despite exhaustive attempts and early 1990s Federal Law (Patient Self-Determination Act) requiring hospitals to enquire from the patient about the existence of advance directives, only $7-18 \%$ of Americans are noted to have executed them. ${ }^{[15]}$ The real impact of these policies on limiting end-of-life care is still uncertain. From a practical point of view, extensive serial discussions with family members are required to achieve consensus. How can similar policies be introduced in India? Lack of awareness and education may be as much a barrier as the lack of relevant laws. DPA is a much better instrument than the living will. We can actually avoid the mistake of attempts at popularizing the living will. The DPA is presented at the time of hospital admission and usually kept in front of the medical chart and all those treating the patient are made familiar with the wishes of the patient. Of course, states would have to be convinced that DPA would prevent painful, intrusive treatments at the endof-life. The effort by the medical personnel will require educating the public, legislators, and judiciary. The medical societies will need to develop policies and be prepared to file amicus briefs in pertinent court cases.

\section{Current practices and future directions}

It is also likely that in the next few years, case law in India will develop to adequately address end-of-life issues. Advances in intensive care and availability of lifesupport technology will force the issues to be confronted both by the public and the medical profession. As part of the urbanization of India, the locale, i.e., where the person actually dies will change. Just as in the West, most people are likely to die in the hospitals and in the ICUs. Another incentive to adopt policies similar to those in the West is the fact that non-Indians may increasingly 
seek medical care in India. Confronted with end-of-life issues, patients, and their loved ones may expect what they consider more enlightened policies.

Consider the current situation in India. It is remarkable that for the moment the Indians are perfectly willing to depend upon cultural attitudes and economic forces to resolve weighty moral issues!

A strong sense of fatalism prevails on the subcontinent. It is not just limited to the Hindus, the dominant faith of the populace. 'Whatever God has willed' is also the professed attitude of many other faiths. Thus acceptance of fate rather struggle for an end is the prevalent attitude. However, it is not likely to remain so. With education will come sophistication and more demanding clientele, who are likely to ask the question 'Isn't there anything else that can be done?' In fact Kapadia et al. offer that in Mumbai, a cosmopolitan, relatively prosperous city, a lot of terminal care in private hospitals is offered to accommodate the relatives of the patient or avoid conflicts with the family. ${ }^{[2]}$

It may be anecdotal experience but one often hears of 'illegality' of discontinuing mechanical ventilation in dying patients in India! ${ }^{[16]}$ In other cases the stories of abrupt withdrawal of life-support systems when families are unable to pay for medical care also abound. Shouldn't we be equally concerned about the immorality of these decisions? One can at least hope for a universal code of medical ethics.

A peculiar designation in India is 'left against medical advice' (LAMA). The practice to take a dying patient home seems to absolve the medical community of responsibility to deal with questions of treatment withdrawal. Most of such decisions are based on acceptance of fate or a lack of money to provide continued care. Mani points out that this represents unilateral withdrawal of care by the family based on lack of financial resources. ${ }^{[1]}$ Even though that statement is true for the most part, complicity of the physicians in this decision is not uncommon. When intensive care becomes universal across India, would the doctors be able to say as they do now that the end is inevitable, survival unprecedented and 'it is time to take the patient home.' That the patients relatives actually take a dying patient home may come as a surprise to the physicians in the West.
Partly, there is a lack of facilities such as hospice and long-term care facilities in India. In developed countries, many of the elderly or disabled patients waiting to die reside in facilities that provide subacute care. The latter is also likely to change in the future. Third-party insurance or affluence of the population will make continuation of life support and other expensive treatments easier to accept. Thus there is a need to examine the ethical basis of decisions at the end-of-life. ${ }^{[16]}$ It is worth noting that the paternalistic European practices which are closer to Indian practices are undergoing a change as well, endorsing a shared decision making process. ${ }^{[17]}$ However, what is needed is a clear-eyed recognition of the responsibilities of the medical profession, which do not diminish just because the family members can no longer afford expensive care. It is suggested that physicians perhaps would have been wiser not to initiate treatment or withdraw it earlier if the prognosis was dismal.

\section{Conclusions}

The end-of-life issues are likely to affect many patients and families in ways not experienced in the past. ${ }^{[14]}$ If we wish to avoid some of the ineffective medical practices in the use of life-support technologies, we need to be aware of the pain and suffering caused by new technologies. The medical profession has a responsibility to use newly available devices and technology wisely, compassionately, and honestly, recognizing its limitations. Guiding the patients and their families both regarding initiation and withdrawal of treatments with aim of diminishing pain and suffering must remain paramount. The fiduciary responsibility of the physicians will not diminish even if universal health insurance becomes the norm.

\section{References}

1. Mani RK. Limitations of life support in the ICU. Ethical issues relating to end of life care. Indian J Crit Care Med 2003;7:112-7.

2. Kapadia F, Singh M, Divatia J, Vaidyanathan P, Udwadia FE, Raisinghaney SJ, et al. Limitations and withdrawal of intensive therapy at the end of life: Practices in intensive care in Mumbai, India. J Crit Care Med 2005;33:1272-5.

3. John Stuart Mill: On Liberty; Pub (1859)-Penguin Classics 1985.

4. Kant E. Foundations of the Metaphysics of Morals- (1785)-Liberal Arts Press 1959-Translated Lewis White Beck-Indianapolis.

5. Veatch RM. Medical Ethics. Pub Jones \& Bartelett: Boston; 1989.

6. Veatch RM. Cross cultural Perspectives in Medical Ethics: Readings. Pub Jones \& Bartelett: Boston; 1989. 
7. Rachels J. The End of Life: Euthanasia and Morality; Pub University Press: Oxford; 1987.

8. Callahan D. The troubled dream of life: living with mortality. Pub Simon \& Schuster; 1993. p. 23.

9. The Council on Ethical \& Judicial Affairs; American Medical Association Medical futility in end-of-life care, report of the council on Ethical \& Judicial Affairs. JAMA 1999;28:937-41.

10. Lynn J. Teno JM, Phillips RS, Wu AW, Desbiens N, Harrold J, et al. Perspectives by family members of the dying experience of older and seriously ill patients. Ann Intern Med 1997;126:97-100.

11. Heyland DK, Rocker GM, O'Callaghan CJ, Dodek PM, Cook DJ. Dying in the ICU: Perspective of Family Members. Chest 2003;124:392-7.

12. Zimmerman JE, Knaus WA, Sharpe SM, Anderson AS, Draper EA, Wagner DP. The use and implications of do not resuscitate orders in intensive care unit. JAMA 1986;255:351-6.

13. Kyff J, Puri VK. Cardiopulmonary resuscitation in hospitalized patients:continuing problems of decision-making. Crit Care Med 1987;15:41-3.

14. Puri VK. DNR Policies: A Procedural Morass. Resuscitation Policies revisited. Indian J Crit Care Med. (In Press)

15. Fagerlin A, Schneider CE. Enough: The failure of the living will. Hastings Center Report 2004;34:30-42.

16. Puri VK. Death in the ICU: Feelings of those Left Behind. Chest 2003;124:11-2.

17. Thomson BT, Cox PN, Antonelli M, Carlet JM, Cassell J, Hill NS, et al. Challenges at end-of-life in the ICU: Statement of the $5^{\text {th }}$ internationational consensus conference in critical care: Brussels, Belgium, Executive Summary. Crit Care Med 2003;32:17814. 